\title{
Helical tomotherapy in patients with leptomeningeal metastases
}

\author{
Sanziana RI Schiopu ${ }^{1,2}$ \\ Gregor $\mathrm{Habl}^{3}$ \\ Matthias Haefner ${ }^{2}$ \\ Sonja Katayama ${ }^{2}$ \\ Klaus Herfarth ${ }^{2,4}$ \\ Juergen Debus ${ }^{2,4}$ \\ Florian Sterzing 4,5
}

'Department of Internal Medicine V, Ludwig-Maximilian University, Munich, Germany; ${ }^{2}$ Department of Radiation Oncology, Heidelberg University, Heidelberg, Germany; ${ }^{3}$ Department of Radiation Oncology, Klinikum rechts der Isar, Technical University, Munich, Germany; ${ }^{4}$ Clinical Cooperation Unit Radiation Oncology, German Cancer Research Center (DKFZ), Heidelberg, Germany; ${ }^{5}$ Radiation Oncology, Kempten Clinic, Kempten, Germany
This article was published in the following Dove Medical Press journal: Cancer Management and Research

\begin{abstract}
Purpose: Leptomeningeal metastasis (LM) is an increasingly common complication of latestage systemic cancer, for which there is no standard treatment. We analyzed outcome and toxicity in patients with LM undergoing craniospinal irradiation via helical tomotherapy (HTCSI) at our institution.
\end{abstract}

Patients and methods: The charts of 15 patients diagnosed with LM and undergoing HT-CSI between 2006 and 2014 were retrospectively assessed. Main neoplasms included breast cancer, lung cancer, and lymphoma. All patients presented with cranial neuropathy due to LM. Followup was performed regularly. Survival analysis was performed by the Kaplan-Meier method, and prognostic factors were tested using the COX-regression model.

Results: Median survival by cancer type was 6 (breast cancer), 1 (lung cancer), and 2 months (lymphoma), respectively. Median overall survival and relapse-free survival were calculated to be between 2 and 3 months. Six- and 12-month survival was 30\% (95\% CI 0.08-0.5) and 20\% (95\% CI $0.05-0.4)$, respectively. Symptom palliation occurred in 53\% of patients in general, but in $67 \%$ of breast cancer patients, in particular. Patients with lung cancer experienced no improvement. Most common acute treatment-related toxicity at different levels were hematological toxicity, multiple cranial neuropathy, fatigue, infections, nausea, and headache.

Conclusion: HT-CSI can help meet the challenge of treating patients with LM, especially because it can palliate symptoms and improve neurological functions. One-year survival remains as disappointing as before.

Keywords: craniospinal irradiation, radiotherapy, palliative care, neoplastic meningitis, breast cancer

\section{Introduction}

Leptomeningeal metastasis (LM) is diagnosed in $1 \%-5 \%$ of patients with solid tumors, $5 \%-15 \%$ of patients with leukemia and lymphoma, and $1 \%-2 \%$ of patients with primary brain tumors. LM results in significant morbidity, and median survival is short despite therapy. ${ }^{1}$ At present, treatment relies on intrathecal methotrexate (MTX), systemic chemotherapy (intravenous), surgery, and radiotherapy (RT) of the cerebral and/or spinal meninges. Helical tomotherapy (HT), a recent development of large-field intensity-modulated radiation therapy, has been used in the Department of Radiation Oncology (University Hospital Heidelberg) since 2006. In contrast to conventional craniospinal irradiation (CSI), HT offers the possibility of irradiating large target volume continuously and homogeneously without gaps and junctions.
Correspondence: Sanziana RI Schiopu Klinikfür Radioonkologie und Strahlentherapie in der Kopfklinik des Universitätsklinikums Heidelberg, Im Neuenheimer Feld 400, 69I20 Heidelberg, Germany

Tel +496221568202

Fax +496221565353

Emailschiopu_s@yahoo.com 
It ensures irradiation of the entire neuraxis in one session and short treatment times coupled with a full $360^{\circ}$ treatment arc. Furthermore, elective dose-reduction to organs at risk (OAR) guarantees control of dose distribution and that OAR are spared. A drawback of HT results from the fact that the machine rotates $360^{\circ}$ around the patient, meaning that radiation is also applied to surrounding normal tissues, above and below the target. ${ }^{2}$ Therefore, while providing highly conformal and homogenous radiation to the target, it is the large low-dose volumes to normal tissues that raises concerns and criticism. ${ }^{3}$ The end points of this retrospective analysis are survival, symptom palliation, and treatment-induced toxicity. Results will be compared with the existing literature.

\section{Materials and methods}

The hospital charts of 15 patients diagnosed with LM (Table 1) and undergoing HT-CSI were retrospectively assessed from 2006 to 2014. Median age at diagnosis was 54 (range 17-75) years. They were primarily suffer-

Table I Patients' characteristics

\begin{tabular}{|c|c|}
\hline Characteristics & \\
\hline Total patients & $15(100 \%)$ \\
\hline \multicolumn{2}{|l|}{ Age (years) } \\
\hline Median & 54 \\
\hline Range & $17-75$ \\
\hline \multicolumn{2}{|l|}{ Gender } \\
\hline Male & $4(26.7 \%)$ \\
\hline Female & II (73.3\%) \\
\hline \multicolumn{2}{|l|}{ Karnofsky Performance Status } \\
\hline Median & 80 \\
\hline Range & $30-90$ \\
\hline \multicolumn{2}{|l|}{ PD } \\
\hline Breast cancer & $9(60 \%)$ \\
\hline Lung cancer & $3(20 \%)$ \\
\hline Non-Hodgkin diffuse large B-cell lymphoma & $2(13.3 \%)$ \\
\hline Alveolar rhabdomyosarcoma & I (6.7\%) \\
\hline \multicolumn{2}{|l|}{ Distant metastatic sites } \\
\hline No & I $(6.7 \%)$ \\
\hline Yes & $14(93.3 \%)$ \\
\hline \multicolumn{2}{|l|}{ Sites of systemic tumor burden beside LM and PD } \\
\hline$\leq 2$ & $\mathrm{II}(73.3 \%)$ \\
\hline$\geq 3$ & $3(20 \%)$ \\
\hline Intracerebral metastases & $8(53.3 \%)$ \\
\hline \multicolumn{2}{|l|}{ Validation of diagnosis } \\
\hline Imaging study only & $2(13.3 \%)$ \\
\hline CSF study only & $0(0 \%)$ \\
\hline Imaging and CSF studies & $13(86.7 \%)$ \\
\hline
\end{tabular}

Abbreviations: CSF, cerebrospinal fluid; LM, leptomeningeal metastases; PD, primary disease. ing from breast and lung cancer, lymphoma, and alveolar rhabdomyosarcoma. Thirteen patients had evidence of LM in both magnetic resonance imaging (MRI) and cerebrospinal fluid (CSF) cytology. In two patients, the diagnosis was based solely on leptomeningeal contrast enhancement in MRI. All patients presented with multiple neuropathy. Most common neurological findings, present in $60 \%$ of patients, were cranial nerve disorders (cranial nerve palsy, cauda equina syndrome), followed by radicular pain (53.3\%), headache $(33.3 \%)$, visual impairment such as diplopia (40\%), vomiting, nausea, seizures, and dizziness (each 13.3\%).

\section{Chemotherapy}

Prior to HT, $12(80 \%)$ patients underwent chemotherapy (CTX) regimes (Table 2) in accordance with the protocols for breast and lung cancer, lymphoma, and alveolar rhabdomyosarcoma. Six (40\%) patients received adjuvant CTX. Concurrent CTX (vincristine, weekly) was administered to the alveolar rhabdomyosarcoma patient. Two patients (13.3\%) did not have CTX at all. A median time of 5.5 months (range 1-43 months) was calculated between the last dose of CTX and initiation of HT.

\section{Craniospinal irradiation via helical tomotherapy}

The indication for craniospinal irradiation via helical tomotherapy (HT-CSI) was alleviation of LM-related symptoms and improvement of CSF flow obstruction. All patients were immobilized in head first supine position, using customized thermoplastic masks with shoulder fixation and an integrated board. The beam on time was $\sim 12$ minutes, while the total session time including computer tomography (CT) image guidance, position correction, and treatment application was around 20-30 minutes. Plain and enhanced CT images with 5-mm slice thickness were taken from overhead to the entire pelvis for treatment planning using Siemens Sensation Open CT. Images were transferred to a Siemens oncologist workstation for contouring. Planning was performed in a Tomotherapy planning work station. The clinical target volume (CTV) included the whole brain, spinal canal, down to S3 and root ganglia. The CTV to planning target volume (PTV) margin was 5, 10, and $20 \mathrm{~mm}$ for head and neck, thorax, and lumbosacral regions, respectively. The time needed for contouring the OAR was 2 hours, for the PTV 1 hour, and the inverse planning took 1 hour. 
Table 2 CTX regimes used before and after HT and the time span between last dose of CTX and initiation of HT

\begin{tabular}{|c|c|c|c|c|}
\hline \multirow{2}{*}{$\begin{array}{l}\text { Patient } \\
\text { number }\end{array}$} & \multirow{2}{*}{$\begin{array}{l}\text { Primary } \\
\text { disease }\end{array}$} & \multicolumn{2}{|l|}{ Chemotherapy regimes } & \multirow{2}{*}{$\begin{array}{l}\text { Time between last } \\
\text { dose of CTX and } \\
\text { initiation of HT } \\
\text { (months) }\end{array}$} \\
\hline & & Before HT or concurrent & After HT & \\
\hline I & $\begin{array}{l}\text { Alveolar } \\
\text { rhabdomyosarcoma }\end{array}$ & $4 \times$ IVADo regime, concurrent & & 7 \\
\hline 2 & Lung cancer & Cisplatin/vinblastin & & NA \\
\hline 3 & Lung cancer & Carboplatin/vinorelbine & & 12 \\
\hline 4 & Lung cancer & No CTX possible (KPS =30\%) & & - \\
\hline 5 & $\begin{array}{l}\text { Non-Hodgkin diffuse } \\
\text { large B-cell lymphoma }\end{array}$ & R-CHOP, $3 \times$ IT MTX & & 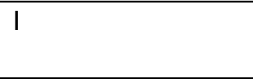 \\
\hline 6 & $\begin{array}{l}\text { Non-Hodgkin diffuse } \\
\text { large B-cell lymphoma }\end{array}$ & R-CHOPI4. MTX, Natulan, CCNU. Depocyte. & & I \\
\hline 7 & Breast cancer & IV MTX & $\begin{array}{l}\text { Cytarabine } \\
\text { liposomal }\end{array}$ & 1 \\
\hline 8 & Breast cancer & No CTX (resection in toto (pT4b pN3a(I / / I5)LI G3 R0) & & - \\
\hline 9 & Breast cancer & $\begin{array}{l}\text { Epirubicin/cyclophosphamide, docetaxel. tamoxifen, and } \mathrm{GnRH} \text { - } \\
\text { analog. Faslodex and } \mathrm{GnRH} \text {-analog. }\end{array}$ & $\begin{array}{l}\text { Capecitabine, } \\
\text { denosumab }\end{array}$ & 43 \\
\hline 10 & Breast cancer & $\begin{array}{l}\text { Epirubicin/paclitaxel/cyclophosphamid. Goserelin, letrozol, } \\
\text { denosumab. }\end{array}$ & & 31 \\
\hline II & Breast cancer & $\begin{array}{l}\text { Cyclophosphamide/MTX/5 fluorouracil (1995). } \\
\text { Docetaxel, trastuzumab, tamoxifen (2003). } \\
\text { Goserelin, anastrozol, exemestan (2006). Capecitabine } \\
(2006-2009) .\end{array}$ & Navelbine & 11 \\
\hline 12 & Breast cancer & Epirubicin/cyclophosphamid/paclitaxel & & 5 \\
\hline 13 & Breast cancer & Cyclophosphamide/MTX/5 fluorouracil & $\begin{array}{l}\text { PEG-liposomal } \\
\text { doxorubicin }\end{array}$ & 6 \\
\hline 14 & Breast cancer & Cisplatin/Gemcitabine & & 5 \\
\hline 15 & Breast cancer & $\begin{array}{l}\text { Paclitaxel. Vinorelbine/denosumab/Avastin. Capecitabine/ } \\
\text { bevacizumab. Everolimus/exemestan/tamoxifen. Fulvestrant/ } \\
\text { bendronat. Letrozol. }\end{array}$ & & 1 \\
\hline
\end{tabular}

Notes: Blank spaces in the "After HT" column mean that there was no chemotherapy after completion of HT. "-" indicates this patient did not receive any chemotherapy, therefore the time between chemotherapy and initiation of HT cannot be calculated or cannot be a number, as there was no chemotherapy.

Abbreviations: HT, helical tomotherapy; IT, intrathecal; IV, intravenous; IVADo, ifosfamide, vincristine, actinomycin D and doxorubicin; KPS, Karnofsky Performance Status; MTX, methotrexate; NA, information not available; R-CHOP, rituximab, cyclophosphamid, hydroxydaunomycin/hydroxydaunorubicin, vincristin, prednison.

\section{Statistical analysis}

Microsoft Excel 2010 was used for descriptive statistics of patient and treatment characteristics: Absolute numbers, percentages, minimum, maximum, mean, median, and standard deviation were calculated. Patients' characteristics included age at diagnosis, gender, tumor type and histology, Karnofsky Performance Status (KPS), M-status, CTX, and hematological indices levels. Treatment parameters were dosimetry (radiation dose to the target volume, to OAR, coverage of target volume), fractionation, fan beam thickness, modulation factors, treatment time, etc. Survival analysis was performed by the Kaplan-Meier method, using the STATA software package (Version 12.1). Main end points were overall survival (OS) and relapse-free survival (RFS). Survival was calculated from the starting point of HT-CSI. Multivariate analysis using the COX regression model was performed in order to determine whether certain factors have a statistically significant impact on survival. A 95\% CI and a significance threshold alpha level of $P=0.05$ were used.

\section{Follow-up}

During treatment, blood routine tests were reviewed weekly and acute side effects were investigated and recorded. Regular follow-up appointments, in accordance with our internal institutional standard, took place every $4-6$ weeks in the first 6 months, every 3 months for approximately the next 2 years, and then annually. They included blood chemistry and routine tests, cerebral enhanced MRI, and spinal cord MRI, if necessary.

\section{Results}

\section{Dosimetry}

HT plans (Tables 3 and 4) had a median dose and number of fractions of 32.4 Gy (range 18-39.6 Gy) and 18 
Table 3 Technical parameters of helical tomotherapy plans

\begin{tabular}{|c|c|c|c|c|c|c|c|c|c|c|c|}
\hline \multicolumn{2}{|c|}{ PTV (Gy) } & 18 & 19.2 & 23.4 & 30.6 & 32 & 32.4 & 34.2 & 35.2 & 36 & 39.6 \\
\hline \multicolumn{2}{|c|}{ Fractions $(n)$} & 10 & 12 & 13 & 17 & 20 & 18 & 19 & 22 & 20 & 22 \\
\hline \multicolumn{2}{|c|}{ Fractionation } & $5 \times 1.8$ & $5 \times 1.6$ & $5 \times 1.8$ & $5 \times 1.8$ & $5 \times 1.6$ & $5 \times 1.8$ & $5 \times 1.8$ & $5 \times 1.6$ & $5 \times 1.8$ & $5 \times 1.8$ \\
\hline \multicolumn{2}{|c|}{ Patients receiving PTV (n) } & 2 & $\mathrm{I}$ & $\mathrm{I}$ & 2 & I & $\mathrm{I}$ & $\mathrm{I}$ & $\mathrm{I}$ & 3 & 2 \\
\hline & $\begin{array}{l}\text { Field width } \\
(\mathrm{cm})\end{array}$ & Pitch & \multicolumn{2}{|c|}{$\begin{array}{l}\text { Planned } \\
\text { modulation } \\
\text { factor }\end{array}$} & \multicolumn{2}{|c|}{$\begin{array}{l}\text { Actual } \\
\text { modulation } \\
\text { factor }\end{array}$} & $\begin{array}{l}\text { Duration } \\
\text { (seconds) }\end{array}$ & $\begin{array}{l}\text { Gantry } \\
\text { rotations }\end{array}$ & \multicolumn{2}{|c|}{$\begin{array}{l}\text { Gantry } \\
\text { period } \\
\text { (seconds) }\end{array}$} & $\begin{array}{l}\text { Monitor units } \\
\text { (MU) }\end{array}$ \\
\hline $\begin{array}{l}\text { Average } \\
\text { (range) } \\
\text { (median) }\end{array}$ & 5 & 0.43 & \multicolumn{2}{|c|}{$\begin{array}{l}2.2 \\
(2-2.5) \\
(2.2) \\
\end{array}$} & \multicolumn{2}{|c|}{$\begin{array}{l}1.8 \\
(1.6-1.94) \\
(1.7)\end{array}$} & $\begin{array}{l}706 \\
(586-845) \\
(696) \\
\end{array}$ & $\begin{array}{l}37.1 \\
(35-39.6 I) \\
(36.8) \\
\end{array}$ & \multicolumn{2}{|c|}{$\begin{array}{l}19.0 \\
(16-22) \\
(19.0) \\
\end{array}$} & $\begin{array}{l}10,076.5 \\
(8,309-12,107) \\
(9,942) \\
\end{array}$ \\
\hline SD & & & \multicolumn{2}{|l|}{0.1} & \multicolumn{2}{|l|}{0.1} & 86.8 & 1.2 & \multicolumn{2}{|l|}{2.2} & $12,9 \mid .8$ \\
\hline
\end{tabular}

Abbreviation: PTV, planning target volume.

Table 4 Dose distribution to the PTV, V90\%, VII0\%, and OAR

\begin{tabular}{|l|l|l|l|}
\hline Radiation volume & Median & Range & SD \\
\hline PTV (Gy) & 32.4 & $18-39.6$ & 7.2 \\
\hline V90\% (\%) & 98.0 & $95-99.0$ & 1.2 \\
\hline VII0\% (\%) & 0.0 & $0.0-20.0$ & 4.9 \\
\hline $\begin{array}{l}\text { Radiation dose to } \\
\text { OAR as \% of PTV }\end{array}$ & & & \\
\hline Right lens & 14.5 & $9-23.3$ & 4.4 \\
\hline Left lens & 12.7 & $8.1-24.74$ & 5 \\
\hline Right eye & 33.3 & $17.5-52.19$ & $1 \mathrm{I} .1$ \\
\hline Left eye & 35 & $12.7-54.06$ & 11.5 \\
\hline Thyroid & 37.9 & $29.3-67.7 \mathrm{I}$ & 13.4 \\
\hline Right lung & 22.6 & $6.0-37.8 I$ & 6.6 \\
\hline Left lung & 20.4 & $6.4-32.76$ & 6.2 \\
\hline Right breast & 14.8 & $12.9-18.03$ & 2.0 \\
\hline Left breast & 11.2 & $9.4-15.98$ & 2.8 \\
\hline Right kidney & 18.6 & $11.6-33.02$ & 6.4 \\
\hline Left kidney & 19.5 & $9.4-29.29$ & 5.5 \\
\hline Esophagus & 58.6 & $28.6-83.54$ & 16.2 \\
\hline Bowel & 35.9 & $19.7-49.5$ & 7.8 \\
\hline Right parotid & 24.5 & $13.5-34.74$ & 5.4 \\
\hline Left parotid & 21.8 & $13.5-30.0$ & 4.2 \\
\hline
\end{tabular}

Abbreviations: OAR, organ at risk; PTV, planning target volume; V90\%, irradiated volume receiving at least $90 \%$ of the total dose; $\mathrm{VII} 10 \%$, irradiated volume receiving $110 \%$ of the total dose.

(range 10-22 fractions), respectively. One patient received restricted spinal radiation to $\mathrm{C} 3-\mathrm{S} 3$ due to previous irradiation. All others received brain and spinal irradiation; $33.3 \%$ of patients $(n=5)$ received a boost. There were four sequential boosts (to various regions of the brain or spine) and one patient required a sequential and an integrated boost to the brain.

Treatment was completed by two-thirds of patients $(\mathrm{n}=10)$, despite occasional pauses due to serious acute toxicity. As a result of severely altered general state, treatment was interrupted in one-third of cases ( $\mathrm{n}=5)$ who, ultimately, deceased. The follow-up time was calculated from the end of treatment until death. Median follow-up was 5 months (2-38 months).

\section{Overall survival and relapse-free survival}

Median OS (Figure 1) added up to 3 months. Six-month survival was $30 \%(95 \%$ CI $0.0826-0.4963)$ and 1 -year survival was $20 \%$ (95\% CI $0.0489-0.4239)$. Five patients died during HT, while 10 survived at least 2 months from day 1 of HT (range 2-34 months). Patients with breast cancer had a median OS of 6 months; for lung cancer patients it was $<1$ month, while for lymphoma patients it reached 2 months.

Compared to the state before HT, neurological symptoms disappeared or were relieved in $8(53.3 \%)$. There was no improvement of neurological symptoms in patients with lung cancer. On the contrary, for two-thirds $(66.7 \%)$ of breast cancer patients, symptoms improved or disappeared. RFS was defined as the number of months from day 1 of HT-CSI characterized by either neurological improvement or stable or decreased size of contrast-enhancing leptomeningeal lesions. Nine patients were considered from this perspective; relapse-free and median RFS were calculated at 1 month (range 0-28 months). Relapse occurred in the following manner: local and distant relapse due to progress of LM and new distant metastases $(n=1)$, distant relapse in the form of new distant metastases $(n=1)$, local relapse only as a result of bone metastases progress $(n=2)$, and relapse of neurological dysfunction $(n=1)$. Information about follow-up was incomplete for four patients.

On the one hand, one-third of patients (lung cancer $n=2$, breast cancer $n=2$, and lymphoma $n=1$ ) did not survive more 
than 1 month and deceased during treatment. All presented with distant metastases; thereof four of five were neurologically impaired. Only one patient had a KPS $>70 \%$ before HT-CSI. No improvement of neurological functions was observed. In fact, HT-CSI induced more complications rather than improving things.

On the other hand, three female patients diagnosed with breast cancer LM survived beyond a year. While MRI investigations during follow-up showed stable disease in all cases, symptoms improved only in two patients. When relapse occurred, it was not due to progress of LM, but rather, to progress of bone metastases. Breast cancer subtypes and features are shown in Table 5.
Multivariate analysis using the COX-regression model was performed to examine the effect of tumor histology, histological subtype, KPS, number of sites and location of distant metastases, adjuvant CTX on OS and RFS. A significance threshold alpha level of $P=0.05$ was used. None of the abovementioned factors reached statistical significance.

\section{Acute toxicity}

Adverse effects were recorded according to the Common Terminology Criteria for Adverse Events guidelines version 4.0. Hematological toxicity was interpreted based on white blood cell count, hemoglobin, and platelet count (Table 6).

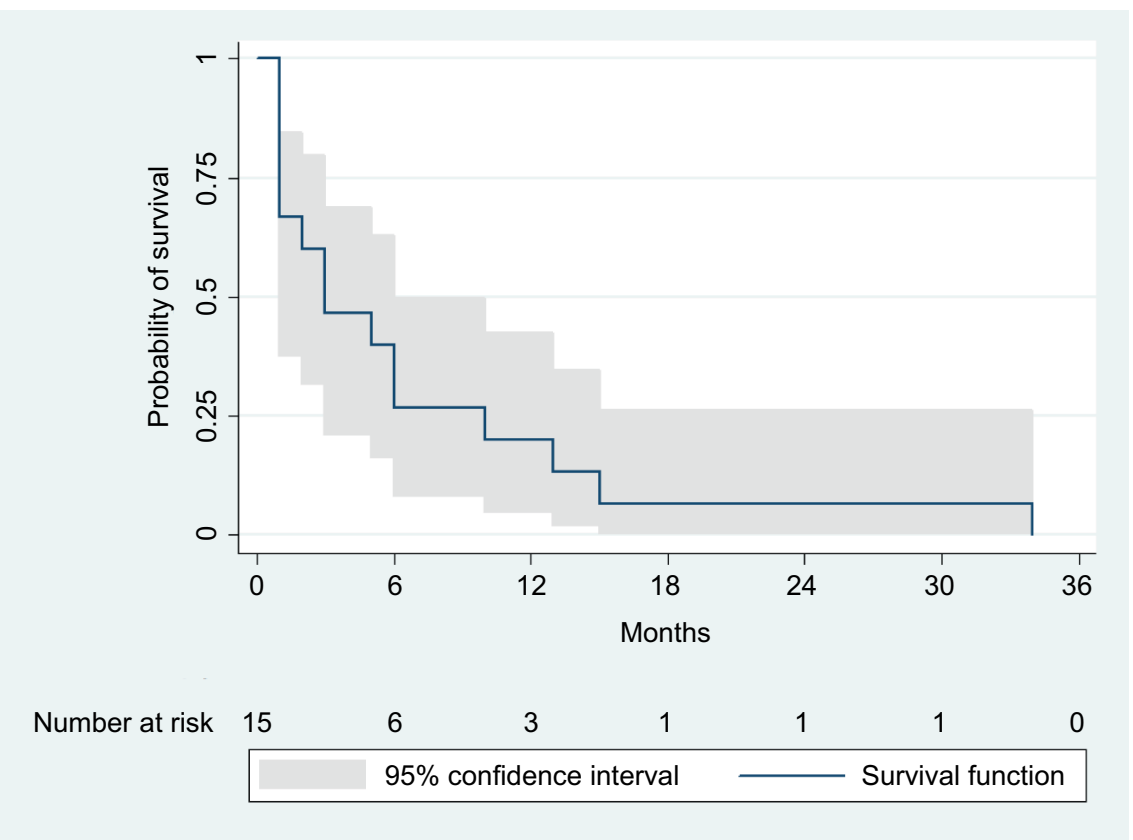

Figure I Kaplan-Meier estimate of overall survival.

Table 5 Breast cancer LM - features of the subgroup

\begin{tabular}{|c|c|c|c|c|c|c|c|}
\hline $\begin{array}{l}\text { Breast cancer tumor } \\
\text { histology }\end{array}$ & ER+/PR+ & HER2 & $\begin{array}{l}\text { Triple } \\
\text { negative }\end{array}$ & $\begin{array}{l}\text { Metastases } \\
\text { other than LM }\end{array}$ & Metastases location & KPS (\%) & OS (months) \\
\hline Adenocarcinoma & + & - & - & Yes & Bone, CNS & 80 & 34 \\
\hline Unknown & + & - & - & Yes & Cerebellum & 80 & 15 \\
\hline Ductal in situ & + & + & - & Yes & $\begin{array}{l}\text { Lung, bone, mediastinal lymph } \\
\text { nodes, ovary }\end{array}$ & 60 & 13 \\
\hline Unknown & NA & NA & NA & Yes & Bone, CNS & 90 & 6 \\
\hline Invasive ductal & - & - & + & No & - & 90 & 6 \\
\hline Infiltrating lobular & - & - & + & Yes & Bone, lymph nodes & 80 & 5 \\
\hline Invasive ductal & NA & NA & NA & Yes & CNS & 90 & 2 \\
\hline Invasive ductal & - & - & + & Yes & $\begin{array}{l}\text { Lung, mediastinum, lymph } \\
\text { nodes, CNS }\end{array}$ & 90 & I \\
\hline Unknown & + & - & - & Yes & Bone, lung, lymph nodes & 60 & 1 \\
\hline
\end{tabular}

Abbreviations: CNS, central nervous system; ER, estrogen receptor; HER2, human epidermal growth factor receptor 2, KPS, Karnofsky Performance Status; LM, leptomeningeal metastasis; NA, information not available, OS, overall survival; PR, progesterone receptor. 


\section{Grades I and 2}

Patients reported one or more HT-related symptoms, which required no in-patient treatment (Figure 2).

\section{Grades 3 and 4}

Serious toxicity (one or more), which made in-patient treatment mandatory, was documented in six patients: nausea/ vomiting/headaches/seizures and nerve palsy $(n=1)$; nausea/ vomiting/headaches/seizures (status epilepticus) and fatigue $(n=1)$; seizures alone $(n=1)$, generalized pain alone $(n=1)$; nerve palsy and neutropenic fever $(n=1)$; nerve palsy and generalized pain $(n=1)$.

\section{Grade 5 toxicity}

There were three treatment associated deaths: two owing to infections like atypical pneumonia or bacterial enteritis and subsequent sepsis and one due to pulmonary embolism despite thrombocytopenia and anticoagulation therapy.

\section{Development of hematological indices}

The evolution of hematological indices (Figure 3) was assessed as much as circumstances allowed: more than half of the patients died during or shortly after treatment and blood routine tests were conducted outside the Heidelberg University Hospital. Transfusion of blood products was needed in

Table 6 Acute hematological toxicity according to the CTCAE guidelines version 4.0, expressed as \% per toxicity level and \% of the whole patient sample

\begin{tabular}{|l|l|l|l|l|l|}
\hline Hematologic toxicity & Toxicity level I & Toxicity level 2 & Toxicity level 3 & Toxicity level 4 & Total (\%) \\
\hline Leukopenia (\% of patients) & 13.3 & 20 & 26.7 & 26.7 & 86.7 \\
\hline Anemia (\% of patients) & 40.0 & 20.0 & 33.3 & 0 & 93.3 \\
\hline Thrombocytopenia (\% of patients) & 26.6 & 26.6 & 20.0 & 26.6 & 100 \\
\hline
\end{tabular}

Abbreviation: CTCAE, Common Terminology Criteria for Adverse Events.

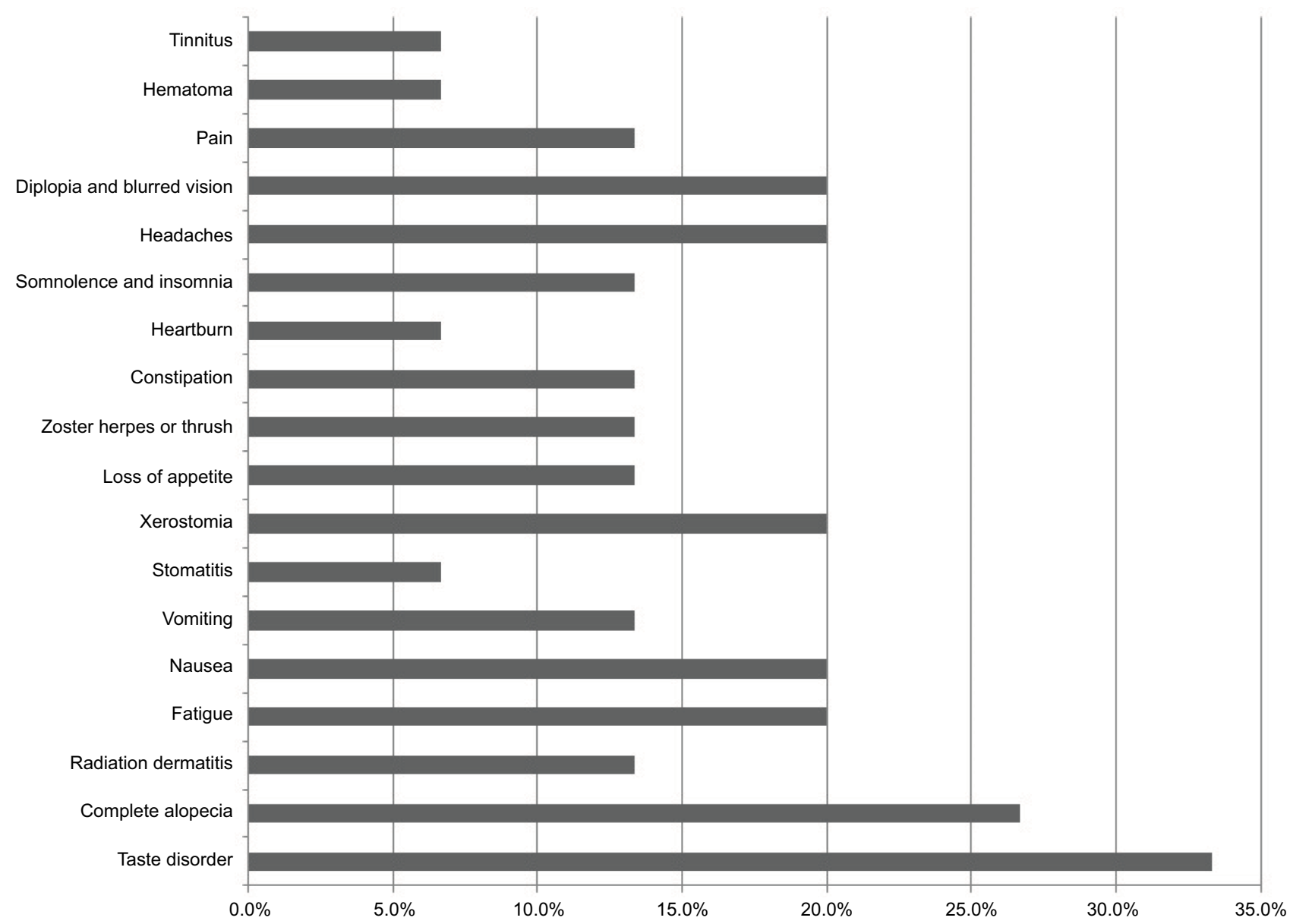

Figure 2 Acute grade I and 2 toxicities, expressed as \% of the whole patient sample; in-patient care was not necessary. 


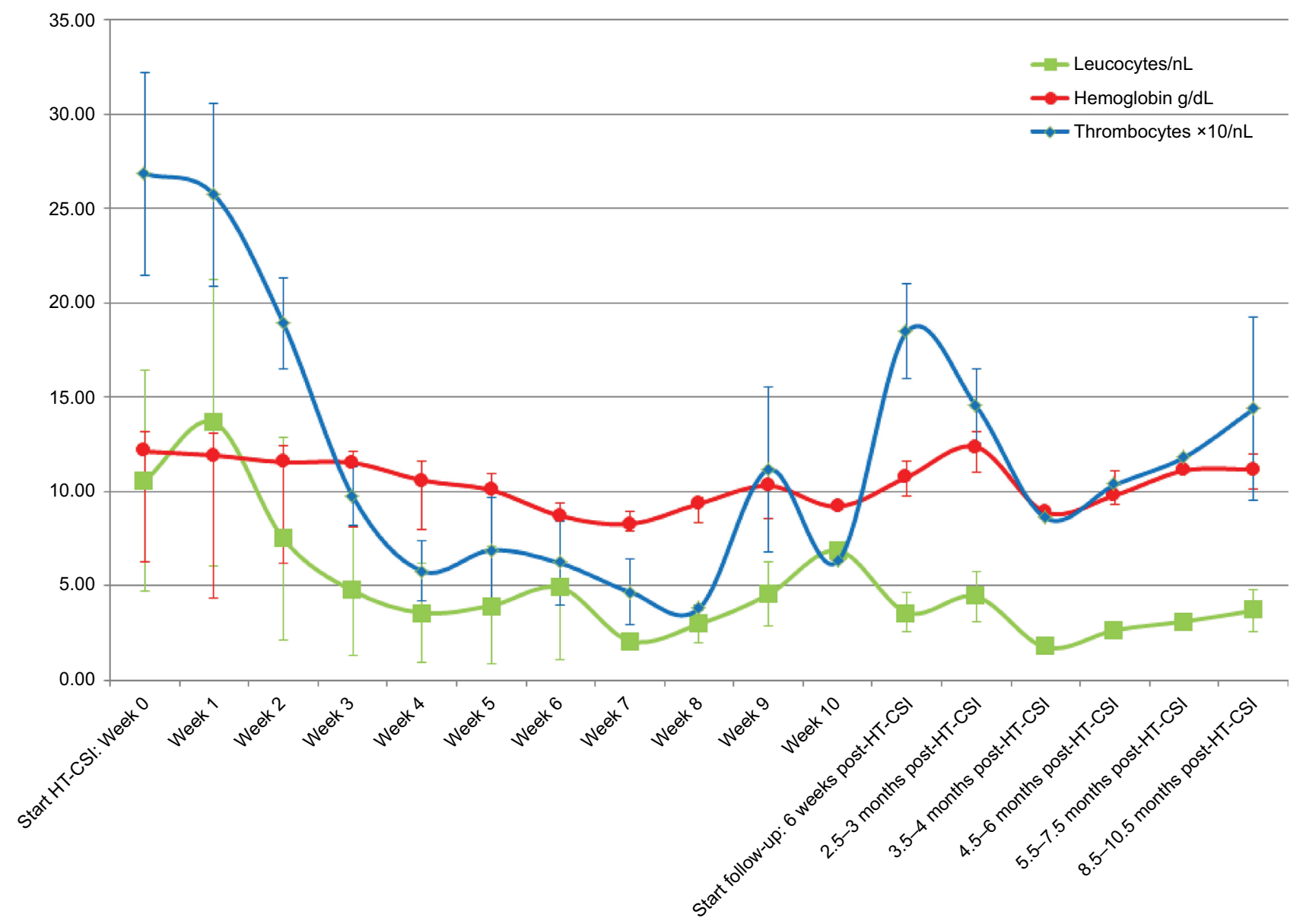

Figure 3 Development of leukocytes, hemoglobin, and platelets.

Abbreviations: HT, helical tomotherapy; HT-CSI, craniospinal irradiation via helical tomotherapy.

$33.3 \%$ of cases $(n=5)$ as follows: red blood cell and/or platelets transfusions $(n=4)$ and granulocyte transfusions $(n=1)$.

\section{Discussion}

The retrospective character of this analysis, small patient sample, and the fact that so far there has not been a standard treatment for LM, makes one formulate conclusions with caution. Whether RT influences survival is still under debate, but more and more research centers have evidence that RT improves quality of life and that CTX and RT offer better treatment results than each separately.

To begin with, RT has been shown to positively impact on quality of life, because it alleviates LM-induced neurological signs and symptoms. ${ }^{46}$ The present analysis confirms these findings, as clinical improvement was observed in 53.3\% of cases treated with HT-CSI.

In a previous analysis at our center, our HT plans showed that conformity and homogeneity of dose distribution to the target volume corroborated by the possibility of sparring adjacent tissues are higher for HT in relation to conventional RT. ${ }^{7}$ In patients with metastatic disease, this may prove to be essential, because conventional RT is limited when preliminary radiotherapies have already been applied to these lesions; or it may be that RT fields by conventional RT are too large in such a case. ${ }^{2}$

Then, no influence of RT, more precisely of neuraxis irradiation, on survival could be established. ${ }^{1,4,8}$ On the one hand, HT as the newest RT technique may change this mentality, given that median and 1-year OS in patients with breast cancer LM appears to have improved. So, for our patients, diagnosed with progressive disease and LM despite antineoplastic treatment, HT was able to extend the median OS to 6 months and 1-year OS reached $20 \%$, superior to what CTX and/or conventional RT can achieve (roughly 4 months and around $10 \%-16 \%$, respectively). ${ }^{4,9-13}$ Interestingly, high-dose MTX does not 
lead to better median OS (3-4 months), but 1-year OS is comparable (around 25\%). ${ }^{8,14}$ On the other hand, when addressing lung cancer patients, median OS is as modest as it was two decades ago (4 weeks) and like then, the benefits of RT are uncertain for lung cancer patients. ${ }^{11}$ Moreover, whether CTX is accompanied by CSI or not, it makes no significant difference in survival (3 months). ${ }^{15}$ When patients achieved a median OS of 17.4 months, it was probably because they were selected based on a KPS $\geq 70 \%$ and no evidence of LM. ${ }^{16}$ In treating lung cancer LM, impressive results (median OS 9 months) seem to be granted by another approach: a combination of EGFR-TKI, VP Shunt, and RT. ${ }^{17}$

After that, pretreatment patient characteristics such as KPS, neurological impairment, distant metastatic sites, systemic CTX, or time between diagnosis of PD and LM have been shown to influence survival, though there has not been agreement since the 1990s regarding which prognostic factor is more significant. ${ }^{4,9,10,18}$ These factors did not achieve statistical significance in the present analysis, but it should be acknowledged that this may be due to the small sample size. Furthermore, it was observed that all the three best performing patients had a KPS $>60 \%$ and an interval $>35$ months between the initial diagnosis of malignant disease and LM. What is more, two of the three best performing patients in the present analysis had a KPS $>70 \%$, metastases to the bones, and no visceral metastases. These factors have been shown to correlate with better survival. The results in the present analysis suggests that the technique employed in CSI may play a part, too, given the fact that median OS thanks to HT was superior to the one reported by the above trials. Furthermore, cranial nerve affection was reported to make a fivefold difference in survival: median OS for patients with neurological symptoms treated with conventional RT was 3.7 weeks as opposed to 19.4 weeks for those without. ${ }^{10}$ But cranial nerve dysfunction was ubiquitous in the patients of this trial and yet a 3-month median OS was achieved.

Finally, it must be acknowledged that toxicity often does not constitute an end point. As a consequence, it should not be mistakenly interpreted that HT-CSI induces more adverse effects, simply because extra attention was paid to precise and detailed reporting of adverse effects. Yet, compared with conventional whole brain RT, HT-CSIinduced toxicity is more frequent and more severe. ${ }^{10}$ Even compared with other HT trials, hematological toxicity grade 3 or higher was more common in the present study. ${ }^{19}$ Even though similar leukopenia was reported, almost 1.5 and 4 times as many patients developed thrombocytopenia and anemia, respectively. Nevertheless, two-thirds of the patients reached normal values again without any transfusion of blood products. Aside from leukocytes and thrombocytes which reached normal values faster (at the end of HT and 1-1.5 months after HT, respectively), hemoglobin followed a pattern also noticed by Qu et al, ${ }^{19}$ namely, 5-6 months after HT. However, CSI appears to be associated with grade 3 and 4 hematological toxicities in patients pretreated with CTX. ${ }^{10}$ In the present study, $80 \%$ of patients underwent several CTX regimes before HT. However, the contribution of CTX to the described toxicities cannot be evaluated due to a short time span between the last CTX application and HT and also to lack of long-term follow-up.

\section{Conclusion}

HT-CSI can help meet the challenge of treating patients with LM, especially because it can palliate symptoms and improve neurological functions. One-year survival remains as disappointing as before. Therefore, going for HT-CSI in treating LM is a very critical decision-making process, and it should be an individual decision. Efforts should focus on diagnosing LM in earlier stages in order to prevent neurological deficits. Further evaluation of HT in a larger patient group should be undertaken.

\section{Ethical approval}

This study was approved by the local ethics committee (Ethics Committee of the Faculty of Medicine of the University of Heidelberg, Germany, S-390/2013). All procedures performed in studies involving human participants were in accordance with the ethical standards of the Ethics Committee of the Faculty of Medicine of the University of Heidelberg and with the 1964 Declaration of Helsinki and its later amendments. Written informed consent was obtained from all individual participants included in the study.

\section{Acknowledgments}

We acknowledge financial support from Deutsche Forschungsgemeinschaft within the Open Access Publishing funding program, the Baden-Württemberg Ministry of Science, Research and the Arts, and from the RuprechtKarls-Universität Heidelberg. Dr Habl is now affiliated with Strahlentherapie Radiologie Muenchen.

\section{Author contributions}

All authors contributed toward data analysis, drafting and critically revising the paper, gave final approval of the version 
to be published, and agreed to be accountable for all aspects of the work.

\section{Disclosure}

The authors report no conflicts of interest in this work.

\section{References}

1. Chamberlain MC. Leptomeningeal metastasis. Curr Opin Oncol. 2010;22(6):627-635.

2. Sterzing F, Schubert K, Sroka-Perez G, Kalz J, Debus J, Herfarth K. Helical tomotherapy. Experiences of the first 150 patients in Heidelberg. Strahlenther Onkol. 2008;184(1):8-14.

3. Sharma DS, Gupta T, Jalali R, Master Z, Phurailatpam RD, Sarin R. High-precision radiotherapy for craniospinal irradiation: evaluation of three-dimensional conformal radiotherapy, intensity-modulated radiation therapy and helical Tomo Therapy. Br J Radiol. 2009;82(984):1000-1009.

4. Niwińska A, Rudnicka H, Murawska M. Breast cancer leptomeningeal metastasis: the results of combined treatment and the comparison of methotrexate and liposomal cytarabine as intra-cerebrospinal fluid chemotherapy. Clin Breast Cancer. 2015;15(1):66-72.

5. Rudnicka H, Niwińska A, Murawska M. Breast cancer leptomeningeal metastasis - the role of multimodality treatment. J Neurooncol. 2007;84(1):57-62.

6. Grant R, Naylor B, Greenberg HS, Junck L. Clinical outcome in aggressively treated meningeal carcinomatosis. Arch Neurol. 1994;51(5):457-461.

7. Schiopu SR, Habl G, Häfner M, et al. Craniospinal irradiation using helical tomotherapy for central nervous system tumors. $J$ Radiat Res. 2017;58(2):238-246.

8. de Azevedo CR, Cruz MR, Chinen LT, et al. Meningeal carcinomatosis in breast cancer: prognostic factors and outcome. J Neurooncol. 2011;104(2):565-572.
9. Meattini I, Livi L, Saieva C, et al. Prognostic factors and clinical features in patients with leptominengeal metastases from breast cancer: a single center experience. J Chemother. 2012;24(5):279-284.

10. Gani C, Müller AC, Eckert F, et al. Outcome after whole brain radiotherapy alone in intracranial leptomeningeal carcinomatosis from solid tumors. Strahlenther Onkol. 2012;188(2):148-153.

11. Liaw CC, Ng KT, Huang JS, Wang CH, Kiu MC, Lai GM. Meningeal carcinomatosis from solid tumors: clinical analysis of 42 cases. J Formos Med Assoc. 1992;91(3):299-303.

12. Le Rhun E, Taillibert S, Zairi F, et al. A retrospective case series of 103 consecutive patients with leptomeningeal metastasis and breast cancer. J Neurooncol. 2013;113(1):83-92.

13. Jo JC, Kang MJ, Kim JE. Clinical features and outcome of leptomeningeal metastasis in patients with breast cancer: a single center experience. Cancer Chemother Pharmacol. 2013;72(1):201-207.

14. GauthierH, Guilhaume MN, BidardFC, etal. Survival of breast cancerpatients with meningeal carcinomatosis. Ann Oncol. 2010;21(11):2183-2187.

15. Morris PG, Reiner AS, Szenberg OR, et al. Leptomeningeal metastasis from non-small cell lung cancer: survival and the impact of whole brain radiotherapy. J Thorac Oncol. 2012;7(2):382-385.

16. Saitoh J, Saito Y, Kazumoto T, et al. Therapeutic effect of linac-based stereotactic radiotherapy with a micro-multileaf collimator for the treatment of patients with brain metastases from lung cancer. Jpn J Clin Oncol. 2010;40(2):119-124.

17. Mitsuya K, Nakasu Y, Mizokami Y, et al. Multidisciplinary treatment of leptomeningeal metastasis in patients with lung adenocarcinoma: the triple modality combination of EGFR-TKI, VP shunt and irradiation. No Shinkei Geka. 2012;40(6):503-509.

18. Boogerd W, Hart AA, van der Sande JJ, Engelsman E. Meningeal carcinomatosis in breast cancer. Prognostic factors and influence of treatment. Cancer. 1991;67(6):1685-1695.

19. Qu B, du L, Huang Y, et al. Clinical analysis of intracranial germinoma's craniospinal irradiation using helical tomotherapy. Chin J Cancer Res. 2014;26(3):247-254.
Cancer Management and Research

\section{Publish your work in this journal}

Cancer Management and Research is an international, peer-reviewed open access journal focusing on cancer research and the optimal use of preventative and integrated treatment interventions to achieve improved outcomes, enhanced survival and quality of life for the cancer patient. The manuscript management system is completely online and includes

\section{Dovepress}

a very quick and fair peer-review system, which is all easy to use. Visit $\mathrm{http}: / /$ www.dovepress.com/testimonials.php to read real quotes from published authors. 